Arq. Bras. Med. Vet. Zootec., v.68, n.1, p.182-190, 2016

\title{
Ganho compensatório no desempenho e eficiência econômica de novilhos Nelore submetidos a diferentes regimes alimentares
}

\author{
[Compensatory gain in performance and economic efficiency of Nellore \\ steers under different feeding regimes] \\ F.A. Barbosa, F.L. Bicalho, D.S. Graça, G.H.B. Maia Filho, H.O. Azevedo, \\ J.M. Leão, J.M.C. Andrade Júnior \\ Escola de Veterinária - Universidade Federal de Minas Gerais - Belo Horizonte, MG
}

\begin{abstract}
RESUMO
Avaliaram-se o efeito do ganho compensatório no desempenho produtivo e a eficiência econômica de novilhos submetidos a diferentes estratégias de suplementação alimentar na fase de recria e engorda. Cinquenta e quatro bezerros, com peso médio inicial de $169,6 \pm 16,7 \mathrm{~kg}$, foram divididos em oito tratamentos, sendo cada tratamento uma estratégia de suplementação alimentar. No período da seca, os animais receberam suplemento proteico-energético-mineral (SP), com ingestão média diária de 0,1 ou $0,2 \%$ do peso vivo. No período das águas, os novilhos receberam SP com ingestão média diária de $0,5 \%$ do peso vivo ou suplementação mineral (SM). No período de terminação, os animais receberam SP com ingestão média diária de $1,4 \%$ do peso vivo ou foram confinados. Os animais que receberam SM não tiveram ganho compensatório. Animais que receberam SP nas águas $(0,51 \pm 0,07 \mathrm{~kg} / \mathrm{dia})$ tiveram ganho compensatório em relação ao período anterior e obtiveram ganho adicional diário de $123 \mathrm{~g}$ quando comparados com SM $(0,39 \pm 0,07 \mathrm{~kg} / \mathrm{dia})$, entretanto não obtiveram ganho compensatório na fase de terminação. O efeito do ganho compensatório é muito pequeno ou até mesmo nulo no sistema de recria e engorda precoce com terminação em confinamento. A suplementação com menor ingestão de proteína, energia e mineral durante a primeira seca e águas, pós-desmame, da vida de novilhos pode ser compensada com o uso do confinamento na fase de terminação desses animais com resultados econômicos positivos.
\end{abstract}

Palavras-chave: bovino de corte, confinamento, pasto, rentabilidade, suplementação

\begin{abstract}
The effect of compensatory growth on performance and economical efficiency of steers on different dietary supplementation strategies in the rearing and fattening stages was evaluated. Fifty-four calves with average initial weight of $169.6 \pm 16.7 \mathrm{~kg}$ were divided into eight treatments, each of them being a strategy of food supplementation. During the dry season the animals received protein - energy - mineral supplement (SP) with an average daily intake of 0.1 or $0.2 \%$ of body weight (BW). During the rainy season the animals received $S P$ with an average daily intake of $0.5 \%$ of body weight or mineral supplementation (SM). In the fattening period, the animals received SP with an average daily intake of $1.4 \%$ of body weight or were placed in feedlot. Animals that received SM had no compensatory gain. Animals that received SP during the rainy season $(0,51 \pm 0,07 \mathrm{~kg} /$ day) had compensatory growth when compared to the previous period, and obtained additional daily gain of $123 \mathrm{~g}$ when compared to SM group $(0,39 \pm 0,07 \mathrm{~kg} /$ day), however did not obtain compensatory gain during the fattening phase. The effect of compensatory gain becomes minimal or zero in feedlot finished. Supplementation strategies with protein, energy and mineral intake in the first dried and the first water in steer's life can be compensated with the use of these animals in the feedlot finishing phase with positive economic results.
\end{abstract}

Keywords: beef cattle, feedlot, pasture, profitability, supplementation

Recebido em 24 de fevereiro de 2015

Aceito em 14 de julho de 2015

E-mail: fabianoalvimvet@hotmail.com 


\section{INTRODUÇÃO}

Ganho compensatório refere-se ao fenômeno manifestado em mamíferos e aves, os quais, após um período de restrição alimentar suficiente para deprimir o crescimento contínuo, apresentam taxa de crescimento acima do normal, ao acabar a restrição e reiniciar uma alimentação adequada (Ben Salem e Smith, 2008).

Vários fatores podem influenciar o ganho compensatório; entre eles, o grau de maturidade em que os animais estão (Almeida et al., 2011), além da severidade e da duração da restrição alimentar (Homem Júnior et al., 2007). Essa restrição refere-se a uma limitação qualitativa ou quantitativa que não permita ao animal expressar seu potencial genético (Pacheco et al., 2005).

Durante o período de restrição alimentar, ocorrem mudanças no perfil hormonal dos animais e redução do tamanho dos órgãos metabolicamente ativos, ligados à função digestiva. A extensão em que ocorre a redução do tamanho desses órgãos influencia a resposta compensatória, em decorrência da relação direta entre o tamanho dos órgãos e as exigências de energia de mantença do animal (Sainz et al., 1995). Oliveira et al. (2004) relataram menores pesos dos compartimentos do trato gastrointestinal (TGI) e do fígado em animais submetidos a pastejo restrito.

A restrição na ingestão de alimentos, apesar de produzir crescimento anormal nos animais, resulta em maiores taxas de crescimento durante o período de realimentação quando comparados com animais que foram alimentados normalmente (Owens et al., 1993). No entanto, o uso dessa estratégia deve ser analisada cuidadosamente, uma vez que, segundo Euclides et al. (1998), o ganho compensatório é, na maioria das vezes, parcial e o uso dessa estratégia está relacionado à idade ao abate dos animais. Bail et al. (2000) verificaram que a restrição alimentar qualitativa no período que antecedeu a terminação em confinamento resultou em aumento do ganho de peso, do consumo e da eficiência alimentar no período subsequente.

A adoção de estratégias de manejo das pastagens e de suplementação propicia aos animais condições para expressar o potencial genético para ganho de peso, ao longo do ano, durante as estações de águas e seca (Reis et al., 2012). A necessidade de prover suplemento proteico, energético e mineral aos bovinos em pastagens e as quantidades a serem fornecidas dependem das metas a serem atingidas de acordo com o planejamento de ganho de peso proposto na propriedade (Barbosa et al., 2007). O ganho em peso do animal deve pagar o desembolso financeiro com a suplementação e os outros custos de produção (Barbosa et al., 2008).

Diante do exposto, objetivou-se avaliar o efeito do ganho compensatório sobre o desempenho produtivo e a eficiência econômica de diferentes estratégias de suplementação alimentar na fase de recria e engorda de novilhos Nelore.

\section{MATERIAL E MÉTODOS}

O experimento foi conduzido na Fazenda Água Limpa, pertencente à Fundação Universidade de Brasília, no período de junho de 2009 a janeiro de 2011. A fazenda está localizada no Distrito Federal, cujas coordenadas geográficas são: $15^{\circ} 55^{\prime} 12.55^{\prime}$ ' latitude sul e $47^{\circ} 55^{\prime} 12.55^{\prime}$ ' longitude oeste. A altitude é de aproximadamente 1.000 metros e o clima é do tipo tropical, apresentando precipitações médias anuais em torno de $1.500 \mathrm{~mm}$. A estação seca foi de junho a novembro do ano de 2009 , e a estação chuvosa foi de novembro de 2009 a julho de 2010.

A área experimental era composta de 12 piquetes de dois hectares cada, estabelecidos com Brachiaria brizantha cv. Marandu e providos de saleiros, bebedouros e cochos para suplementação. Foram utilizados dois currais de confinamento (área de $20 \mathrm{~m}^{2} /$ animal), cocho de concreto coberto para fornecimento de alimentos e bebedouro com água à vontade regulada por boia automática. Foram utilizados 54 bezerros desmamados da raça Nelore, com sete meses e meio de idade e peso vivo médio inicial de $169,6 \pm 16,7 \mathrm{~kg}$.

O período experimental teve duração máxima de 591 dias, o qual foi dividido em três períodos com duas estratégias alimentares por período. $\mathrm{Na}$ primeira seca, os animais foram divididos em dois grupos, sendo alimentados com suplemento proteico-energético-mineral com ingestão média diária de 0,1 ou $0,2 \%$ do peso vivo (PV) por 140 
dias. No período das águas, os animais foram redistribuídos em dois novos grupos, sendo alimentados com suplemento mineral ou proteico-energético-mineral, com ingestão média diária de $0,5 \%$ do PV por 266 dias. Na segunda seca (fase de terminação), os animais foram reagrupados e divididos em confinamento por 110 dias ou semiconfinamento por 185 dias, totalizando oito tratamentos com diferentes estratégias alimentares (Tab. 1).

O delineamento experimental utilizado foi o inteiramente ao acaso, com oito tratamentos de três a 10 repetições, sendo as médias dos tratamentos comparadas por meio do teste de Tukey a $5 \%$ de significância, com o peso inicial dos animais como covariável. $\mathrm{O}$ modelo matemático utilizado foi: $Y_{i j}=\mu+T_{j}+P I_{\mathrm{j}}+e_{i j}$, em que: $Y_{i j}=$ ganho de peso e peso final do animal $\mathrm{j}$ pertencente ao tratamento $\mathrm{i} ; \mu=$ efeito médio; $\mathrm{T}_{\mathrm{i}}=$ efeito fixo do tratamento $\mathrm{i} ; \mathrm{PI}_{\mathrm{j}}=$ covariável peso inicial do animal $\mathrm{j} ; \mathrm{e}_{\mathrm{ij}}=$ erro aleatório associado ao tratamento i a cada animal $\mathrm{j}$.
Os animais foram vermifugados e receberam vacinações preventivas. Foi adotado o sistema de pastejo contínuo, porém, a cada 14 dias, os animais de cada tratamento foram rotacionados nos piquetes como forma de eliminar o efeito de piquete. A taxa de lotação média na primeira seca foi de 0,9 unidade animal (UA) de $450 \mathrm{~kg}$ por hectare (ha), na primeira época das águas foi de 1,3UA/ha e na terminação dos animais em semiconfinamento a taxa média foi de 2,0UA/ha. As pesagens dos animais foram realizadas a cada 28 dias, após jejum alimentar de 24 horas e jejum hídrico de 16 horas.

Os suplementos foram fornecidos no cocho três vezes por semana. A composição dos suplementos e os valores nutricionais são apresentados na Tab. 2. Na terminação, os animais passaram por um período de adaptação às dietas experimentais de aproximadamente 21 dias. No confinamento, as dietas eram fornecidas três vezes ao dia $(7 \mathrm{~h} 30,10 \mathrm{~h} 30$ e $15 \mathrm{~h} 30)$.

Tabela 1. Tratamentos (TRAT) experimentais em função do período e da estratégia alimentar

\begin{tabular}{clll}
\hline Trat & \multicolumn{1}{c}{ Primeira seca } & \multicolumn{1}{c}{ Primeira água } & \multicolumn{1}{c}{ Terminação } \\
\hline A & $\begin{array}{l}\text { Sup. proteico-energético-mineral } \\
\text { de } 0,1 \% \text { do PV }\end{array}$ & $\begin{array}{l}\text { Sup. proteico-energético-mineral } \\
\text { de } 0,5 \% \text { do PV }\end{array}$ & Confinamento \\
B & $\begin{array}{l}\text { Sup. proteico-energético-mineral } \\
\text { de } 0,1 \% \text { do PV }\end{array}$ & $\begin{array}{l}\text { Sup. proteico-energético-mineral } \\
\text { de } 0,5 \% \text { do PV }\end{array}$ & Semiconfinamento \\
C & $\begin{array}{l}\text { Sup. proteico-energético-mineral } \\
\text { de } 0,1 \% \text { do PV }\end{array}$ & Suplementação mineral & Confinamento \\
D & $\begin{array}{l}\text { Sup. proteico-energético-mineral } \\
\text { de } 0,1 \% \text { do PV }\end{array}$ & Suplementação mineral & Semiconfinamento \\
E & $\begin{array}{l}\text { Sup. proteico-energético-mineral } \\
\text { de } 0,2 \% \text { do PV }\end{array}$ & $\begin{array}{l}\text { Sup. proteico-energético-mineral } \\
\text { de } 0,5 \% \text { do PV }\end{array}$ & Confinamento \\
F & $\begin{array}{l}\text { Sup. proteico-energético-mineral } \\
\text { de } 0,2 \% \text { do PV }\end{array}$ & $\begin{array}{l}\text { Sup. proteico-energético-mineral } \\
\text { de } 0,5 \% \text { do PV }\end{array}$ & Semiconfinamento \\
G & $\begin{array}{l}\text { Sup. proteico-energético-mineral } \\
\text { de } 0,2 \% \text { do PV }\end{array}$ & Suplementação mineral & Confinamento \\
H & $\begin{array}{l}\text { Sup. proteico-energético-mineral } \\
\text { de } 0,2 \% \text { do PV }\end{array}$ & Suplementação mineral & Semiconfinamento \\
\hline
\end{tabular}
Sup. $=$ Suplemento, $\mathrm{PV}=$ Peso vivo.

Os consumos dos suplementos proteicoenergético-minerais e do mineral foram calculados pela soma das quantidades de suplemento fornecidas, diminuída da sobra e dividida pelo número de cabeças e pelo número de dias. No confinamento, foi feita a mensuração do consumo médio da dieta de cada tratamento por meio da quantidade de alimento fornecida, que foi ajustada diariamente com base no consumo observado no dia anterior; as sobras foram pesadas diariamente.

Foi feita avaliação da disponibilidade de matéria seca dos piquetes no primeiro dia de cada 
período experimental. Para tanto, mediante o corte a $5 \mathrm{~cm}$ do solo, retiraram-se oito amostras compreendidas em um retângulo metálico de 0,5 x 1,0m, alocado aleatoriamente de acordo com metodologia proposta por McMeniman (1997). Dessa amostra total foram retiradas duas subamostras representativas, subamostra verde e subamostra composta. Na subamostra composta, foi avaliado o percentual das frações da matéria seca verde (MSV) e da matéria seca morta (MSM).

Tabela 2. Proporção dos ingredientes e composição químico-bromatológica do suplemento mineral (SM), suplemento proteico-energético-mineral fornecidos a 0,$1 ; 0,2 ; 0,5$ e 1,4 em porcentagem de peso vivo $(\%$ $\mathrm{PV}$ ) e da dieta de confinamento (Conf)

\begin{tabular}{|c|c|c|c|c|c|c|}
\hline \multirow{2}{*}{ Ingredientes $(\%)$} & \multicolumn{6}{|c|}{ Suplementos e dieta do confinamento } \\
\hline & SM & $0,1 \% \mathrm{PV}$ & $0,2 \% \mathrm{PV}$ & $0,5 \% \mathrm{PV}$ & $1,4 \% \mathrm{PV}$ & Conf \\
\hline Silagem de milho & - & - & - & - & - & 30 \\
\hline Milho moído & - & 47,74 & 0,65 & - & 43,5 & 43,27 \\
\hline Casca de soja & - & - & - & 90,66 & 10,5 & 13,18 \\
\hline Farelo de girassol & - & - & - & - & - & 10,8 \\
\hline Farelo de soja & - & - & 51,78 & - & - & - \\
\hline Caulim & - & 11,5 & 16,27 & - & - & - \\
\hline Ureia & - & 13,45 & 5 & 2,67 & - & 1,05 \\
\hline Suplemento mineral & 45 & 15 & 15 & 2,86 & - & - \\
\hline Sal branco & 55 & 10,76 & 10,75 & 2,86 & - & - \\
\hline Calcário & - & - & - & - & - & 0,7 \\
\hline Sulfato de amônio & - & 1,55 & 0,55 & 0,95 & - & - \\
\hline $\begin{array}{c}\text { Núcleo } \\
\text { proteico-mineral }\end{array}$ & - & - & - & - & 46 & - \\
\hline Núcleo confinamento & - & - & - & - & - & 1 \\
\hline Total $(\%)$ & 100 & 100 & 100 & 100 & 100 & 100 \\
\hline \multicolumn{7}{|c|}{ Composição nutricional } \\
\hline MS (\%) & - & 92,51 & 92,75 & 85,53 & 88,2 & 57,21 \\
\hline PB (\%) & - & 45,23 & 42,11 & 20,83 & 18,5 & 13,9 \\
\hline FDN $(\%)$ & & & & & - & 36,68 \\
\hline FDA $(\%)$ & & & & & - & 30,82 \\
\hline
\end{tabular}

$\mathrm{MS}=$ matéria seca, $\mathrm{PB}$ = proteína bruta, FDN = fibra em detergente neutro e FDA = fibra em detergente ácido.

As amostras de forragem dos alimentos que compõem as dietas experimentais e as sobras do confinamento foram analisadas, nas metodologias descritas por Detmann et al. (2012), quanto ao teor de matéria seca (MS), proteína bruta $(\mathrm{PB})$, fibra em detergente neutro (FDN) e fibra em detergente ácido (FDA).

Foram utilizadas planilhas eletrônicas do Programa Microsoft Excel ${ }^{\circledR}$ para estimar os indicadores econômicos. Foram consideradas como despesas: valor de compra dos animais, valor de arrendamento das pastagens, suplementos minerais e proteico-energéticos, ração concentrada, volumoso do confinamento, medicamentos e mão de obra.

O valor médio dos bezerros desmamados foi de $\mathrm{R}$ \$ 424,38/cabeça, o valor do arrendamento da pastagem foi de $\mathrm{R} \$ 15,00 /$ cabeça/mês, o custo por aplicação dos medicamentos foi de R\$4,00/cabeça/aplicação. Os custos dos suplementos foram de $\mathrm{R} \$ 0,77 / \mathrm{kg}$ para o suplemento com ingestão diária de $0,1 \%$ do PV; R\$ $0,76 / \mathrm{kg}$ para o suplemento com ingestão diária de $0,2 \%$ do $\mathrm{PV} ; \mathrm{R} \$ 0,39 / \mathrm{kg}$ para o suplemento com ingestão diária de $0,5 \%$ do PV e $\mathrm{R} \$ 0,36 / \mathrm{kg}$ para o suplemento com ingestão diária de $1,4 \%$ do $\mathrm{PV}$. $\mathrm{O}$ custo do suplemento mineral foi de $\mathrm{R} \$ 1,17 / \mathrm{kg}$, e o custo da dieta do confinamento foi de $\mathrm{R} \$ 3,50 /$ bovino/dia.

Foram considerados os valores reais de 2009 para compra de insumos e os valores reais referentes à venda dos animais de 2010 e 2011 . Para estimativa do custo com mão de obra, foi considerado salário referente aos anos de 2009 a 2011 com encargos sociais, em 4,0 horas/homem/dia para todos os tratamentos 
correspondentes ao tempo para fornecimento da alimentação.

Considerou-se o valor de arroba de boi gordo no dia do abate, sendo o valor de venda dos animais de $\mathrm{R} \$ 3,66 / \mathrm{kg}$ para os animais engordados em confinamento e R $\$ 3,33 / \mathrm{kg}$ para os animais engordados em semiconfinamento. Para a análise econômica, foi calculado o resultado de caixa, sendo o resultado da receita subtraído da despesa do fluxo de caixa, do valor presente líquido (VPL) e da taxa interna de retorno (TIR). Para o cálculo do VPL, foi considerada uma taxa de juros de $0,56 \%$ ao mês.

\section{RESULTADOS E DISCUSSÃO}

Os valores médios da disponibilidade de matéria seca total (MST) e matéria seca verde (MSV) da Brachiaria brizantha cv. Marandu para os períodos da primeira seca, primeira água e da terminação foram de $4,72,4,77$ e 5,85 ton/ha e $0,62,0,99$ e 0,86 ton/ha, respectivamente. A disponibilidade de MST da forragem não foi limitante para desempenho dos animais, apresentando valores acima de duas toneladas de $\mathrm{MST} / \mathrm{ha}$, estando de acordo com Flores et al. (2008). Pelo pastejo simulado, foi observado que os teores de PB, FDN e FDA variaram, apresentando valores de $6,49 \% \mathrm{~PB}, 77,31 \% \mathrm{FDN}$ e 43,6\% FDA no período das águas, de 4,35\% PB, 70,64\% FDN e 39,2\% FDA no período da seca e de $5,65 \%$ PB, $74,13 \%$ FDN e $42,27 \%$ FDA na terminação.

Durante o primeiro período seco, todos os animais ganharam peso. Os animais que foram suplementados com $0,2 \%$ do PV apresentaram ganho superior $(\mathrm{P}<0,05)$, quando comparados ao grupo de animais que foi suplementado com 0,1 $\%$ do PV (Tab. 3). O aumento no ganho de peso ocorreu pela maior ingestão do suplemento e, consequentemente, pelo crescente consumo de nutrientes, principalmente PB. Essa observação está de acordo com Moore et al. (1999), os quais afirmaram que a resposta à suplementação (proteína, energia e mineral) para ganho de peso é maior quando a suplementação proporciona consumo de proteína bruta maior que $0,05 \%$ do $\mathrm{PV}$, e é positiva quando esse consumo for maior que $0,1 \%$ do $P V$.
No período das águas, os animais que receberam $0,5 \%$ do PV de suplementação proteicoenergética-mineral apresentaram peso vivo final e ganho de peso superior $(\mathrm{P}<0,05)$ quando comparados com os animais que receberam apenas suplementação mineral (Tab. 3). Esses animais apresentaram um ganho adicional de 59 a $174 \mathrm{~g}$ por dia e terminaram o período das águas 12,61 a $46,02 \mathrm{~kg}$ mais pesados quando comparados com os animais que receberam apenas suplementação mineral. Animais frequentemente respondem à suplementação de proteína extra durante a estação das águas, proporcionando ganhos adicionais diários de 200 a 300g/animal (Paulino et al., 2005).

Dentro do grupo de animais que receberam apenas suplementação mineral no período das águas, não houve efeito de ganho compensatório em relação ao período seco anterior (Tab. 3). No tratamento em que os animais receberam suplementação proteico-energético-mineral com $0,5 \%$ do PV no primeiro período das águas (A, $\mathrm{B}, \mathrm{E}$ e F), houve efeito de ganho compensatório em relação ao período seco anterior; esse ganho compensatório foi total, sendo o ganho médio diário (GMD) e o peso final (PF) superiores $(\mathrm{P}<0,05)$. Os animais que receberam suplementação com ingestão de $0,1 \%$ do $\mathrm{PV}$ no período anterior apresentaram GMD adicional no período das águas de $42 \mathrm{~g}$ e um PF de $11,12 \mathrm{~kg}$ superior aos animais que receberam suplementação com ingestão de $0,2 \%$ do PV no período seco anterior. O crescimento do animal é retardado em consequência de subnutrição; quando cessa essa restrição alimentar, o animal cresce normalmente a uma taxa mais acelerada, podendo apresentar uma compensação parcial ou até mesmo total (Euclides et al., 1998).

No período da terminação, não houve diferença $(\mathrm{P}>0,05)$ para $\mathrm{PF}$ e GMD entre o grupo de animais que recebeu $0,5 \%$ do $\mathrm{PV}$ de suplementação proteico-energético-mineral (SP) e o grupo suplementado com mineral (SM) durante o período das águas (Tab. 3), o que pode ser explicado pelos ganhos de peso contínuos acima de 360g/dia durante as águas. Esses resultados corroboram os verificados por Fontes et al. (2007), os quais avaliaram efeito de ganho compensatório de novilhos Holandês-Gir que foram confinados posteriormente ao período de recria em pastagens. 
Tabela 3. Médias para peso vivo, inicial e final, e ganho de peso diário dos novilhos durante o primeiro período da seca, água e terminação (confinamento e semiconfinamento)

\begin{tabular}{|c|c|c|c|c|}
\hline \multicolumn{5}{|c|}{ Primeira seca } \\
\hline \multirow{2}{*}{ Tratamentos } & \multicolumn{2}{|c|}{ Peso vivo $(\mathrm{kg})$} & \multirow{2}{*}{\multicolumn{2}{|c|}{ Ganho de peso diário (g/animal/dia) }} \\
\hline & Início & Fim & & \\
\hline E, F, G e H $(0,2 \%)$ & 169,38 & $203,04 \mathrm{a}$ & \multicolumn{2}{|c|}{$0,239 \mathrm{a}$} \\
\hline A, B, C e D $(0,1 \%)$ & 169,75 & $194,01 \mathrm{~b}$ & \multicolumn{2}{|c|}{$0,174 \mathrm{~b}$} \\
\hline \multicolumn{5}{|c|}{ Primeira água } \\
\hline \multirow{2}{*}{ Tratamentos } & \multicolumn{2}{|c|}{ Peso vivo final $(\mathrm{kg})$} & \multicolumn{2}{|c|}{ Ganho de peso diário (g/animal/dia) } \\
\hline & SM & SP & SM & SP \\
\hline E, F, G e H $(0,2 \%)$ & $316,96 \mathrm{Ba}$ & $329,57 \mathrm{Ab}$ & $0,434 \mathrm{Ba}$ & $0,493 \mathrm{Ab}$ \\
\hline A, B, C e D $(0,1 \%)$ & $294,67 \mathrm{Bb}$ & $340,69 \mathrm{Aa}$ & $0,361 \mathrm{Bb}$ & $0,535 \mathrm{Aa}$ \\
\hline \multicolumn{5}{|c|}{ Terminação } \\
\hline \multirow{3}{*}{ Tratamento } & \multicolumn{4}{|c|}{ Peso vivo $(\mathrm{kg})$} \\
\hline & & \multicolumn{2}{|c|}{ Peso vivo final } & \multirow{2}{*}{ Média } \\
\hline & Peso vivo inicia & Conf & Semiconf & \\
\hline SM & 305,81 & $432,95 \mathrm{Ba}$ & $467,06 \mathrm{Aa}$ & 450 \\
\hline SP & 335,13 & $449,91 \mathrm{Ba}$ & $483,55 \mathrm{Aa}$ & 466,73 \\
\hline \multirow{3}{*}{ Média } & & 441,43 & 475,3 & \\
\hline & \multicolumn{4}{|c|}{ Ganho de peso diário (kg/animal/dia) } \\
\hline & & Conf & Semiconf & Média \\
\hline SM & & $1,092 \mathrm{Aa}$ & $0,896 \mathrm{Ba}$ & 0,994 \\
\hline SP & & $1,010 \mathrm{Aa}$ & $0,792 \mathrm{Ba}$ & 0,901 \\
\hline Média & & 1,051 & 0,844 & \\
\hline \multicolumn{5}{|c|}{$\begin{array}{l}\text { Médias seguidas de letras distintas, maiúsculas na mesma linha e minúsculas na mesma coluna, diferem entre si } \\
\text { estatisticamente para teste de Tukey a } 5 \% \text { de probabilidade. Siglas: E, F, G e H: os animais receberam suplemento } \\
\text { proteico-energético-mineral na quantidade diária de } 0,2 \% \text { do peso vivo na primeira seca. A, B, C e D: os animais } \\
\text { receberam suplemento proteico-energético-mineral na quantidade diária de } 0,1 \% \text { do peso vivo no período da primeira } \\
\text { seca. SM- tratamentos A, B, E e F, em que os animais receberam suplemento mineral no período das águas; SP- } \\
\text { tratamentos A, B, E e F, em que os animais receberam suplemento proteico-energético-mineral na quantidade diária } \\
\text { de } 0,5 \% \text { do peso vivo no período das águas; Conf - tratamentos A, C, E e G, em que os animais foram confinados no } \\
\text { período da terminação; Semiconf - tratamentos B, D, F e H, em que os animais receberam suplemento proteico- } \\
\text { energético-mineral na quantidade diária de } 1,4 \% \text { do peso vivo no período da terminação. }\end{array}$} \\
\hline
\end{tabular}

Foram observadas diferenças $(\mathrm{P}<0,05)$ entre os tratamentos para o $\mathrm{PF}$, sendo os maiores valores para os tratamentos $\mathrm{F}, \mathrm{B}$ e $\mathrm{H}$ em relação ao $\mathrm{C}$ (Tab. 4). O menor $\mathrm{PF}$ do tratamento $\mathrm{C}(\mathrm{P}<0,05)$ está relacionado à menor quantidade de nutrientes ingerida com a suplementação na primeira seca, com ingestão de $0,1 \%$ do $\mathrm{PV}$, apenas suplementação mineral nas águas $\mathrm{e}$, posteriormente, com os animais engordados em confinamento, sendo este tratamento com o menor nível de suplementação alimentar durante o período de pastejo. Durante o confinamento, esses animais não conseguiram alcançar $o$ mesmo peso final dos outros tratamentos. Os animais dos tratamentos $\mathrm{B}, \mathrm{D}, \mathrm{F}$ e $\mathrm{H}$ que apresentaram $\mathrm{PF}$ superior receberam suplementação proteico-energético-mineral de $1,4 \%$ PV em semiconfinamento, sendo abatidos aos 27 meses de idade e, portanto, permanecendo 70 dias a mais no experimento quando comparados com os tratamentos em que os animais foram engordados em confinamento.

Resende et al. (2008) trabalharam com novilhos durante a fase de recria e terminação com diferentes estratégias de suplementação e de terminação (confinamento e no pasto) e observaram que o uso de suplemento proteicoenergético, fornecido a $0,5 \%$ do $\mathrm{PV} / \mathrm{dia}$, tanto na seca, como nas águas, reduziu a idade de abate de novilhos em mais de 100 dias nos animais confinados em relação aos terminados no pasto.

Os animais terminados em confinamento atingiram peso final de abate aos 746 dias de idade, obtendo maior preço de venda do boi gordo (entressafra) em relação aos animais terminados em semiconfinamento abatidos aos 816 dias de idade. 
Tabela 4. Desempenho de novilhos Nelore na fase de recria e engorda para peso inicial (PI), peso final $(\mathrm{PF})$, ganho médio diário acumulado (GMD) e idade ao abate nos diferentes tratamentos

\begin{tabular}{cclcc}
\hline Tratamentos & PI $(\mathrm{kg})$ & \multicolumn{1}{c}{ PF $(\mathrm{kg})$} & GMD $(\mathrm{kg})$ & Idade ao abate (dias) \\
\hline A & 170,0 & $457,3 \mathrm{ab}$ & $0,511 \mathrm{a}$ & 746 \\
B & 170,0 & $475,1 \mathrm{a}$ & $0,515 \mathrm{a}$ & 816 \\
C & 169,0 & $418,8 \mathrm{~b}$ & $0,479 \mathrm{a}$ & 746 \\
D & 168,0 & $461,0 \mathrm{ab}$ & $0,495 \mathrm{a}$ & 816 \\
E & 166,0 & $442,5 \mathrm{ab}$ & $0,529 \mathrm{a}$ & 746 \\
F & 169,0 & $492,0 \mathrm{a}$ & $0,546 \mathrm{a}$ & 816 \\
G & 170,0 & $447,2 \mathrm{ab}$ & $0,532 \mathrm{a}$ & 746 \\
H & 176,0 & $473,1 \mathrm{a}$ & $0,502 \mathrm{a}$ & 816 \\
\hline
\end{tabular}

Médias seguidas de letras distintas, na mesma coluna, diferem entre si estatisticamente pelo teste de Tukey a $5 \%$ de probabilidade.

Os maiores retornos econômicos foram dos tratamentos $\mathrm{G}$ e $\mathrm{C}$, nos quais os animais receberam suplemento proteico-energéticomineral na primeira seca, suplemento mineral no período das águas e terminação em confinamento; o VPL foi de R $\$ 252,10, \mathrm{R} \$$ 230,55 , respectivamente, e a TIR de $2,45 \%$ e
$2,36 \%$ ao mês, sendo esses valores obtidos pelo maior resultado de caixa (Tab. 5). Os animais do tratamento B apresentaram os menores resultados de VPL e TIR, sendo R $\$ 92,00$ e $1,16 \%$ ao mês, respectivamente, apesar de terem obtido maior PF.

Tabela 5. Média de despesas, receita, resultado de caixa, valor presente líquido (VPL) e da taxa interna de retorno (TIR) dos diferentes tratamentos.

\begin{tabular}{ccccccccc}
\hline Despesas (R\$) & \multicolumn{7}{c}{ Tratamentos } \\
\cline { 2 - 9 } & $\mathrm{A}$ & $\mathrm{B}$ & $\mathrm{C}$ & $\mathrm{D}$ & $\mathrm{E}$ & $\mathrm{F}$ & $\mathrm{G}$ & $\mathrm{H}$ \\
\hline $\begin{array}{c}\text { Compra de } \\
\text { animais }\end{array}$ & 425,00 & 425,00 & 422,50 & 420,00 & 415,00 & 422,50 & 425,00 & 440,00 \\
$\begin{array}{c}\text { Suplementos } \\
\text { Mão de obra }\end{array}$ & 103,45 & 530,65 & 460,48 & 378,54 & 628,34 & 546,34 & 476,17 & 394,17 \\
$\begin{array}{c}\text { Medicamentos } \\
\text { Arrendamento }\end{array}$ & 115,00 & 210,71 & 103,46 & 115,71 & 103,46 & 115,71 & 103,46 & 115,71 \\
\hline Subtotal (A) & 1367,00 & 1390,00 & 216,00 & 20,00 & 16,00 & 20,00 & 16,00 & 20,00 \\
\hline Receita (R\$) & & 1212,44 & 1234,00 & 210,00 & 300,00 & 210,00 & 300,00 \\
\hline $\begin{array}{c}\text { Venda de } \\
\text { animal (B) }\end{array}$ & 1676,77 & 1583,67 & 1535,42 & 1536,67 & 1622,50 & 1640,00 & 1639,59 & 1577,07 \\
\hline $\begin{array}{c}\text { Resultado de } \\
\text { caixa (B-A) }\end{array}$ & 309,77 & 192,32 & 323,02 & 302,42 & 249,81 & 235,46 & 349,00 & 307,13 \\
\hline VPL (R\$) & 212,02 & 92,00 & 230,55 & 198,77 & 157,48 & 129,40 & 252,10 & 199,57 \\
\hline TIR (\%) & 2,09 & 1,16 & 2,36 & 1,91 & 1,72 & 1,37 & 2,45 & 1,96 \\
\hline
\end{tabular}

TIR - taxa interna de retorno ao mês. VPL - valor presente líquido.

Os valores econômicos deste estudo assemelham-se aos obtidos por Euclides et al. (1998) e Figueiredo et al. (2007), que encontraram maiores retornos econômicos para os tratamentos com maior nível de suplementação com proteína, energia e mineral. Da mesma forma, Ítavo et al. (2008), ao avaliarem diferentes suplementos proteicoenergético-minerais, obtiveram lucro de R\$ 19,78/@ de PV para os animais que receberam suplemento à base de minerais + ureia + milho e
R\$18,15/@ de PV para os animais que receberam apenas suplementação mineral.

De acordo com Almeida et al. (2010), animais que passaram por restrição alimentar e apresentam menor escore de condição corporal deveriam ser mais valorizados por invernistas e confinadores, já que, potencialmente, podem ter ganho compensatório. Os tratamentos que apresentaram efeito do ganho compensatório (A, B, E e F) obtiveram resultado de caixa positivo, 
no entanto a estratégia de comercialização (época de venda) exerceu influência no resultado econômico, pois o ganho de peso e o peso final não diferiram $(\mathrm{P}>0,05)$, sendo os valores de VPL de $\mathrm{R} \$ 212,02$ e R\$ 92,00 e TIR de 2,09 e 1,16\% para os tratamentos A (confinados) e B (semiconfinados), respectivamente (Tab. 5). Nessa situação, o ganho compensatório pode ser explorado quando os animais recebem menores quantidades de suplementação na primeira seca e são terminados na segunda seca em regime de confinamento, permitindo concluir que de outras formas o ganho compensatório não se justifica do ponto de vista econômico.

\section{CONCLUSÃO}

O efeito do ganho compensatório é muito pequeno ou até mesmo nulo no sistema de recria e engorda precoce com terminação em confinamento. A suplementação com menor ingestão de proteína, energia e mineral durante a primeira seca e primeira água da vida de novilhos pode ser compensada com o uso do confinamento na fase de terminação desses animais, com resultados econômicos positivos.

\section{REFERÊNCIAS}

ALMEIDA, R.; MEDEIROS, S.R.; LANNA, D.P.D. Crescimento compensatório e seu efeito na eficiência. In: PIRES, A.V. (Ed.). Bovinocultura de corte. Piracicaba: FEALQ, 2010. p.171- 181.

ALMEIDA, T.R.V.; PEREZ, J.R.O.; CHLAD, M. et al. Desempenho e tamanho de vísceras de cordeiros Santa Inês após ganho Compensatório. Rev. Bras. Zootec., v.40, p.616-621, 2011.

BAIL, C.A.T.; BRONDANI, I.L.; RESTLE, J. Níveis de concentrado na fase de terminação em confinamento para novilhos previamente mantidos em pastagem nativa ou cultivada. Cienc. Rural, v.30, p.151-157, 2000.

BARBOSA, F.A.; GRAÇA, D.S.; GUIMARÃES, P.H.S; SILVA JÚNIOR, F.V. Análise econômica da suplementação proteico-energética de novilhos durante o período de transição entre água-seca. Arq. Bras. Med. Vet. Zootec., v.60, p.911-916, 2008.
BARBOSA F.A.; GRAÇA, D.S.; MAFFEI, W.E. et al. Desempenho e consumo de matéria seca de bovinos sob suplementação proteico-energética, durante a época de transição água-seca. Arq. Bras. Med. Vet. Zootec., v.59, p.160-167, 2007.

BEN SALEM, H.; SMITH, T. Feeding strategies to increase small ruminant production in dry environments. Small Ruminant Res., v.77, p.174194, 2008.

DETMANN, E.; SOUZA, M.A.; VALADARES FILHO, S.C. et al. Métodos para análise de alimentos. Visconde do Rio Branco: Suprema, 2012. 214p.

EUCLIDES, V.P.B.; EUCLIDES, K.; ARRUDA, Z.J.; FIGUEIREDO, G.R. Desempenho de novilhos em pastagens de Brachiaria decumbens submetidos a diferentes regimes alimentares. Rev. Bras. Zootec., v.27, p.246-254, 1998.

FIGUEREDO, M.D.; OLIVEIRA, A.S.; SALES, M.F.L. et al. Análise econômica de quatro estratégias de suplementação para recria e engorda de bovinos em sistema pastosuplemento. Rev. Bras. Zootec., v.36, p.14431453, 2007.

FLORES, R.S.; EUCLIDES, V.P.B.; ABRÃO, M.P.C. et al. Desempenho animal, produção de forragem e características estruturais dos capins Marandu e Xaraés submetidos a intensidades de pastejo. Rev. Bras. Zootec., v.37, p.1355-1365. 2008.

FONTES, C.A.A.; GUIMARÃES, R.F.M.; ALMEIDA, M.I.V. et al. Avaliação do ganho compensatório em novilhos mestiços HolandêsGir: consumo e desempenho. Rev. Bras. Zootec., v.36, p.698-708, 2007.

HOMEM JUNIOR, A.C.; SILVA SOBRINHO, A.G.; YAMAMOTO, S.M. et al. Ganho compensatório em cordeiras na fase de recria: desempenho e medidas biométricas. Rev. Bras. Zootec., v.36, p.111-119, 2007.

ÍTAVO, L.C.V.; TOLEMTINO, T.C.P.; ÍTAVO, C.C.B.F. et al. Consumo, desempenho e parâmetros econômicos de novilhos Nelore e F1 Brangus $\mathrm{x}$ Nelore terminados em pastagens, suplementados com mistura mineral e sal nitrogenado com ureia ou amireia. Arq. Bras. Med. Vet. Zootec., v.60, p.419-427, 2008. 
MCMENIMAN, N.P. Methods of estimating intake of grazing animals. In: SIMPÓSIO SOBRE TÓPICOS ESPECIAIS EM ZOOTECNIA, 1997, Juiz de Fora. Anais... Juiz de Fora: SBZ, 1997. p.133-168.

MOORE, J.E.; BRANT, M.H.; KUNKLE, W.E.; HOPKINS, D.I. Effects of supplementation on voluntary forage intake, diet digestibility, and animal performance. J. Anim. Sci., v.77, p.122135,1999

OLIVEIRA, L.O.F.; SALIBA, E.O.S.; RODRIGUEZ, N.M. et al. Consumo e digestibilidade de novilhos Nelore sob pastagem suplementados com misturas múltiplas. Arq. Bras. Med. Vet. Zootec., v.56, p.61-68, 2004.

OWENS, F.N.; DUBESKI, P.; HANSON, C.F. Factors that alter the growth and development of ruminants. J. Anim. Sci., v.71, p.3138-3150, 1993.

PACHECO, P.S.; RESTLE, J.; SILVA, J.H.S. et al. Desempenho de novilhos jovens e superjovens de diferentes grupos genéticos terminados em confinamento. Rev. Bras. Zootec., v.34, p.963-975, 2005.
PAULINO, M.F.; MORAIS, E.H.B.K.; ZERVOUDAKIS, J.T. et al. Fontes de energia em suplementos múltiplos de auto-regulação de consumo na recria de novilhos mestiços em pastagens de Brachiaria decumbens durante o período das águas. Rev. Bras. Zootec., v.34, p.957-962, 2005.

RESENDE, F.D.; SAMPAIO, R.L.; SIQUEIRA, G.R. et al. Estratégias de suplementação na recria e terminação de bovinos de corte. Efeitos do nível de suplementação na recria sobre o desempenho na terminação. In: REUNIÃO DA SOCIEDADE BRASILEIRA DE ZOOTECNIA, 45., 2008, Lavras. Anais... Lavras: Sociedade Brasileira de Zootecnia. 2008. p.45.

REIS, R.A.; RUGGIERI, A.C.; OLIVEIRA, A.A. et al. Suplementação como estratégia de produção de carne de qualidade em pastagens tropicais. Rev. Bras. Saude. Prod. Anim., v.13, p.642-655, 2012.

SAINZ, R.D.; LA TORRE, F.; OLTJEN, J.W. Compensatory growth and carcass quality in growth-restricted and reefed beef steers. J. Anim. Sci., v.73, p.2971-2979, 1995. 